\title{
La función modal y evidencial del pretérito imperfecto. Un análisis de corpus basado en CREA
}

\author{
Verónica Böhm ${ }^{1}$ \\ Universidad de Potsdam/Instituto de Romanistica, Alemania
}

\begin{abstract}
Resumen
En algunos casos, el pretérito imperfecto puede hacer referencia implícita al conocimiento indirecto que tiene el hablante sobre la situación expresada en su enunciado (función modal) y marcar así una fuente de información externa sin mencionarla (función evidencial). De este modo, el hablante se distancia del contenido de su enunciado y se restringe el valor de verdad del enunciado. En esta contribución se realizará un análisis cuantitativo y también cualitativo de la función modal y evidencial del pretérito imperfecto sobre la base del corpus en línea de la Real Academia Española (CREA) de la sección 'periódicos' del español peninsular. El uso modal y evidencial del pretérito imperfecto será explicado y analizado mediante algunos ejemplos representativos (análisis cualitativo) y se proveerán datos estadísticos sobre estos usos (análisis cuantitativo). Asimismo, se observará si el pretérito imperfecto puede expresar por sí solo la función modal y evidencial o necesita el apoyo de elementos contextuales a nivel oracional que corroboren con el significado modal y evidencial. Tanto para el corpus cualitativo como cuantitativo se han escogido los verbos puntuales y perfectivos, como reconocer, ascender, pagar, morir y estallar porque estos verbos compatibilizan mejor con una forma verbal perfectiva (cf.
\end{abstract}

\footnotetext{
1 Para correspondencia, dirigirse a: Verónica Böhm (veronica.boehm@uni-potsdam.de),
} Universidad de Potsdam, Am Neuen Palais 10, 14469 Potsdam, Alemania. 
NGLE 2009: 1763) y sus usos son muy inusuales en la forma verbal imperfectiva (en pretérito imperfecto). De este modo, se constatará también si sus usos en pretérito imperfecto pueden motivar alguna función modal y evidencial.

Palabras clave: pretérito imperfecto, modalidad epistémica, evidencialidad, corpus cuantitativo-cualitativo

\title{
THE MODAL AND EVIDENTIAL FUNCTION OF THE SPANISH IMPERFECT. A CORPUS-BASED ANALYSIS USING CREA
}

\begin{abstract}
In some cases, the Spanish imperfect can implicitly make reference to the indirect speaker's knowledge about the situation expressed in his utterance (modal function), thus marking an external information source without mentioning it (evidential function). In this way, the speaker dissociates himself from the content of his utterance and the truth-value of the utterance is constrained. In this contribution a quantitative and qualitative analysis of the modal and evidential function of the Spanish imperfect based on the Corpus of the Real Academia Española (CREA) of the section 'periódicos' and of the peninsular Spanish will be made. The modal and evidential use of the Spanish imperfect will be explained and analyzed through some representative examples (qualitative analysis) and statistical data about theses uses will be provided (quantitative analysis). Furthermore, it will be observed if the Spanish imperfect can express the modal and evidential function by its own or if it needs some contextual elements at the sentence level which corroborate the modal and evidential meaning. Both for the qualitative and quantitative corpus punctual and perfective verbs, such as reconocer ('to recognize'), ascender ('to rise'), pagar ('to pay'), morir ('to die') and estallar ('to explode') have been chosen because they combine better with the perfective form (cf. NGLE 2009: 1763) and their uses in the imperfective form (in the Spanish imperfect) is very uncommon. It will be also proved if their uses in the Spanish imperfect can motivate some modal and evidential function.
\end{abstract}

Keywords: Spanish imperfect; epistemic modality; evidentiality; quantitative-qualitative corpus

Recibido: 01/02/20 Aceptado: 01/10/20 


\section{INTRODUCCIÓN}

La función modal y evidencial del pretérito imperfecto ya no está relacionada con sus valores primarios o prototípicos - cuando es usado como un 'copretérito' o una forma verbal 'relativa' del pasado (valor temporal) o expresa una situación en su transcurso que es vista en su duración y sin término (valor aspectual imperfectivo)- sino más bien con la actitud epistémica del hablante frente al contenido de su enunciado, o sea, con su conocimiento o saber sobre la situación expresada en su enunciado (función modal) y con la fuente de información, cuando esta fue adquirida o transmitida por terceros, es decir, cuando es de evidencia indirecta (función evidencial). Reyes (1990: 17) y Gutiérrez Aráus (1995a, 1995b: 179-183), entre otros, se refieren, en este sentido, a la función citativa del pretérito imperfecto por llevar implícito un discurso anterior:

(1) Mañana se iba Jorge a Chile.

(1a) [Me dijeron que] mañana se iba Jorge a Chile. (Reyes 1990: 17)

La función citativa del pretérito imperfecto está asociada con la actitud pragmática del hablante frente a lo que dice: a) mostrando una incertidumbre sobre el conocimiento de lo que enuncia o b) no queriendo asumir la responsabilidad sobre la verdad o falsedad de un juicio o información (Gutiérrez Aráus 1995b: 179). Con el pretérito imperfecto se indica implícitamente que el conocimiento sobre la situación expresada "procede del testimonio de otro" (Reyes 1994: 12):

(2) Vuestra boda era para dentro de cuatro meses, ¿no?

(2a) Me informasteis de que vuestra boda sería dentro de cuatro meses. (Gutiérrez Aráus 1995b:180)

Por otro lado, Díaz Salgado (2000: 1) se refiere al uso del pretérito imperfecto como una estrategia comunicativa o una técnica que permite a los informadores "no sólo enmascarar los conceptos [...] sino disfrazar la realidad entera". De este modo, el pretérito imperfecto parece ser "el tiempo verbal más adecuado en nuestro idioma [español] para producir en el oyente la impresión de que lo que se le cuenta no le afecta en absoluto" (Díaz Salgado 2000: 1). Compárense los siguientes ejemplos:

(3) Peres reconocía ayer que el presidente sirio, Hafez El Assad, será el gran ausente de la cumbre, si bien ha sido informado por Mubarak de todos los detalles. (CREA, La Vanguardia, 02/02/1995, Política) 
(4) Juppé reconoció ayer que los ingresos fiscales “están en una auténtica situación de siniestro", al no haberse cumplido las previsiones de crecimiento. (CREA, La Vanguardia, 30/09/1995, Economía y Hacienda)

Ambos enunciados anteriores (3) y (4) se refieren a enunciados dichos por otras personas en el pasado, pero no contienen el mismo significado semántico: Mediante reconocía (cf. ejemplo 3), el hablante se distancia de su enunciado, no asumiendo la responsabilidad de lo que dice, mientras que en (4) el hablante se responsabiliza completamente de lo que dice. Con el pretérito imperfecto reconocía (cf. ejemplo 3 ) la situación es presentada sin término y está abierta con respecto a su validez y conclusión, pero con el pretérito perfecto simple reconoció (cf. ejemplo 4) la situación se entiende como terminada y concluida.

Hasta ahora se ha estudiado mucho sobre el uso del pretérito imperfecto en discursos orales, como Reyes (1990, 1994), Gutiérrez Aráus (1995a, 1995b), Fernández Ramírez (1986), García Fernández (2004) para el español; Bertinetto (1986) y Bazzanella (1990) para el italiano y Bres (2005) para el francés, entre otros. Todos estos estudios coinciden en el uso pragmático y discursivo del pretérito imperfecto que está relacionado con la actitud del hablante frente a su interlocutor, como por ejemplo, el 'imperfecto de cortesía' para expresar cortesía: A mi juicio, estos errores debían ser perdonados (Gutiérrez Aráus 1995b: 181) o el 'imperfecto de deseo' para expresar un deseo: ¡De buena gana me iba mañana al Caribe! (Gutiérrez Aráus 1995b: 181).

No obstante, no se ha estudiado mucho sobre el uso del pretérito imperfecto en textos escritos, sobre todo en textos periodísticos, donde no se puede observar directa e inmediatamente la postura o actitud del hablante frente a lo que dice. A diferencia del discurso oral donde el hablante actúa inmediata y directamente con su interlocutor y se observa con facilidad la actitud pragmática (intención) del hablante frente a su interlocutor, en los textos escritos la comunicación no es directa e inmediata; la interacción del autor (emisor) con el lector ocurre cuando este lee lo escrito, lo que dificulta observar o saber la intención o actitud del hablante frente a lo escrito (lo que dice). En el discurso periodístico escrito se producen informaciones o noticias sobre situaciones reales que ocurrieron u ocurren en algún momento en el tiempo y que son de carácter público, por lo que la noticias deben ser breves, concisas y objetivas. En este sentido, se sugiere el análisis del uso del pretérito imperfecto en textos periodísticos para observar la actitud del hablante con respecto a lo que dice, es decir, con respecto al contenido de su información. Como se tratan de noticias escritas que pueden proceder 
de otras fuentes es interesante observar la postura que tiene el hablante (en este caso, el periodista) al emitir estas noticias siendo él muy pocas veces el autor original de las mismas. En estos ejemplos (5-6), así como en el ejemplo anterior (3), se puede observar que el uso del pretérito imperfecto parece 'anormal', pues ambos enunciados expresan situaciones concluidas que tuvieron lugar en algún momento en el pasado, por lo que se esperaría el uso de una forma verbal perfectiva, como el pretérito perfecto simple:

(5) En este sentido, "Diario 16" llegaba [llegó] a asegurar ayer que Conde amenazó el teniente general Emilio Alonso Manglano, director del Cesid, con que tendría que "atenerse a las consecuencias" si no declaraba a favor de sus tesis ante el Supremo en la investigación del caso Crillon. (CREA, La Vanguardia, 16/06/1995, Política)

(6) Pocos días después estallaba [estalló] la intifada, y la consiguiente represión israelí hacía imposible la independencia en la segunda fecha elegida por los palestinos, el 15 de noviembre. (CREA, La Voz de Galicia, 18/12/2000, Política)

En ambos enunciados (5-6) el pretérito imperfecto está modalizado y expresa funciones relacionadas con la actitud del hablante frente a lo que dice (modalidad) y su referencia a la fuente de información (evidencialidad).

En esta contribución se analizará cuantitativa y cualitativamente el uso del pretérito imperfecto en textos periodísticos (escritos) tomados del corpus de la Real Academia Española (CREA).

\author{
2. HIPÓTESIS DE PARTIDA: \\ DE LA 'INDETERMINACIÓN SEMÁNTICA' \\ AL VALOR MODAL DEL PRETÉRITO IMPERFECTO
}

La hipótesis de partida para el valor modal del pretérito imperfecto es su naturaleza aspectual imperfectiva ${ }^{2}$ junto con su rasgo temporal relativo: Por a) su rasgo aspectual imperfectivo, el pretérito imperfecto presenta una

\footnotetext{
2 La oposición aspectual corresponde a las formas verbales 'cantó' de aspecto perfectivo que contempla la acción en su totalidad desde una perspectiva externa; y 'cantaba' de aspecto imperfectivo que muestra la acción en curso (cursividad), en su proceso, sin considerar el inicio o final de la misma (cf. Comrie 1976).
} 
situación en su curso y duración sin explicitar el inicio o final de la misma y b) por su rasgo temporal que viene dado por su naturaleza deíctica, referencial, o anafórica, la denotación temporal del pretérito imperfecto está vinculado con otra situación pasada. De ahí a considerar el pretérito imperfecto como un tiempo relativo, el cual da la idea de 'trasfondo' o de 'circunstancia' o de 'subordinación' de una situación, como por ejemplo en "Cuando sonó el teléfono, el mayordomo bajaba las escaleras o En ese preciso momento, el mayordomo bajaba las escaleras"(NGLE 2009: 1737). Justamente es la idea de trasfondo o circunstancia y el rasgo aspectual imperfectivo del pretérito imperfecto que permiten su modalización o su interpretación modal (y evidencial): Una acción o situación vista en su transcurso, en su duración, donde el inicio y final de la situación no están marcados, la cual da la idea de trasfondo y circunstancia de una situación, hacen que la situación se vea como inconclusa y abre paso al valor modal del pretérito imperfecto, tal y como se observa en el ejemplo (7) de Gutiérrez Aráus (1995a: 51) sobre el 'imperfecto de conato' o de 'acción inminente frustada':

(7) Ana salía, cuando sonó el teléfono.

En el enunciado (7), se entiende que la acción de 'salir' era una mera intención del hablante, la cual puede haberse realizado o no, ya que, aparentemente, fue interrumpida por la acción de 'sonar el teléfono'. Esto puede entenderse mejor si reformulamos la oración (7) y contextualizamos su finalización:

(7a) Ana salía, cuando sonó el teléfono, y no pudo salir.

(7b) Ana salía, cuando sonó el teléfono, y lo dejó sonar y se fue.

La indeterminación semántica ${ }^{3}$ del pretérito imperfecto abre la posibilidad de considerar la situación (expresada en pretérito imperfecto) como indeterminada o abierta con respecto a su validez: "This semantic indeterminacy opens up the possibility to view the presented process with respect to its validity as undetermined and open" (Haßler 2012: 136). En el siguiente enunciado (8), por ejemplo, no se sabe si el hablante llegó a comer un trozo de pan y beber un vaso de leche, pues esta disposición de hacerlo fue interrumpida cuando en la puerta se oyeron tres fuertes golpes:

\footnotetext{
3 Bajo el término de 'indeterminación semántica' entendemos que el pretérito imperfecto no expresa límites cognitivos de espacio y tiempo, o por lo menos estos límites no se encuentran enfocados (cf. Böhm 2016: 235, también Dessì 2010: 42).
} 
(8) Siempre me ha gustado el pan untado con mantequilla y espolvoreado de azúcar, y aquella tarde, al regresar del colegio, me dispuse a comer un trozo y a beber un vaso de leche. En ello estaba cuando sonaron en la puerta de calle tres fuertes golpes (Corpus del Español) ${ }^{4}$

García Fernández (2004), tomando en cuenta algunos estudios como los de Bertinetto (1986: 346), Bazanella (1990: 455) y Reyes (1990: 33), también establece un vínculo entre la aspectualidad imperfectiva del pretérito imperfecto y la modalidad: "Los casos de imperfectos modalizados parecen, pues, en cierto modo, sostener la hipótesis aspectual, puesto que, como hemos visto, son varios los autores que se han ocupado de este problema y que han establecido un vínculo entre imperfectividad y modalización" (García Fernández 2004: 94). Este vínculo semántico entre la aspectualidad imperfectiva o indeterminación semántica y la modalidad es denominado por Dessí (2010: 60) "puente metonímico" (cf. también Böhm 2016: 23). Haßler (2012: 141) utiliza el término de metonymic bridge para explicar la contigüidad de dos funciones: "imperfective aspectuality leads to modality due to its indeterminacy" ("la aspectualidad imperfectiva conduce a la modalidad debido a su indeterminación', Haßler 2012: 141). De acuerdo a Bazzanella (1990: 455), la indeterminación semántica del pretérito imperfecto permite una transferencia del mundo real al mundo creado por el hablante. De ahí que el pretérito imperfecto pueda ser usado con valores modales en diversos contextos, como por ejemplo, en vez de otras formas verbales:

- como presente para expresar sorpresa: ¡Pero si eras tú!,

- como futuro para expresar deseo: ¡A esta gentuza la metía yo en la cárcel toda su vida! (Gutiérrez Aráus 1995b: 181),

- como condicional para expresar algo hipotético: Yo que vosotros, no pagaba esa multa,

- como 'imperfecto lúdico': Yo era Blancanieves y tú el principe,

- como 'imperfecto onírico' o de 'sueño': Ieri notte ho sognato cose strane. Camminavo per una strada piena di fiori rossi, mentre ad un tratto incontravo Giulia che mi chiedeva di raccoglierne uno per lei (cf. Bazanella 1990), entre otros.

4 Solo en este caso específico, por la originalidad del ejemplo, se utilizó un ejemplo del Corpus del Español (https://www.corpusdelespanol.org/). 
Estos valores modales del pretérito imperfecto han sido tratados y estudiados por algunos estudiosos y lingüistas en diversas literaturas bajo una diferente terminología como por ejemplo, valores secundarios y metafóricos por Bello (1988: \& 670); valori modali dell'Imperfetto por Bertinetto (1986: 368-380); valores modales por Reyes (1990: 29-42) y por RAE (NGLE 2009: 17481755); atypical or non-canonical uses por Bazzanella (1990: 439); valores secundarios por Gutiérrez Aráus (1995b: 177-183); usos dislocados por Rojo y Veiga (1999: 2913-2918) y por Leontaridi (2001: 215-239).

La relación o vínculo semántico que existe entre la indeterminación semántica y la modalidad parece radicar en los siguientes aspectos:

a) La indeterminación semántica dada por la aspectualidad imperfectiva del pretérito imperfecto presenta una situación como indeterminada e incierta en cuanto a su validez, como el ejemplo (7) anterior: Ana salía, cuando sonó el teléfono.

b) La modalidad -como lo veremos a continuación en el cap. 3.1- está relacionada con la actitud validativa del hablante respecto al contenido de su enunciado, presentando una situación con offene Geltung ('validez abierta') (Volkmann 2005: 60). En el siguiente enunciado (9), el hablante no expresa ningún juicio con respecto a la verdad de la situación expresada en el enunciado, lo que puede estar relacionado con el desconocimiento o incertidumbre que tiene el hablante sobre la situación (modalidad epistémica), es decir, el valor de verdad de la situación está abierto o indeterminado con respecto a su validez:

(9) Creo que Ana está en casa. (Volkmann 2005: 60)

Entonces, el 'común denominador' entre la aspectualidad imperfectiva (indeterminación semántica) y la modalidad es presentar una situación con offene Geltung ('validez abierta'). El siguiente cuadro (1) basado en Böhm (2016: 321) es un intento de visualizar el paso (puente metonímo) de la aspectualidad imperfectiva a la modalidad, donde se encuentra el valor modal del pretérito imperfecto: 


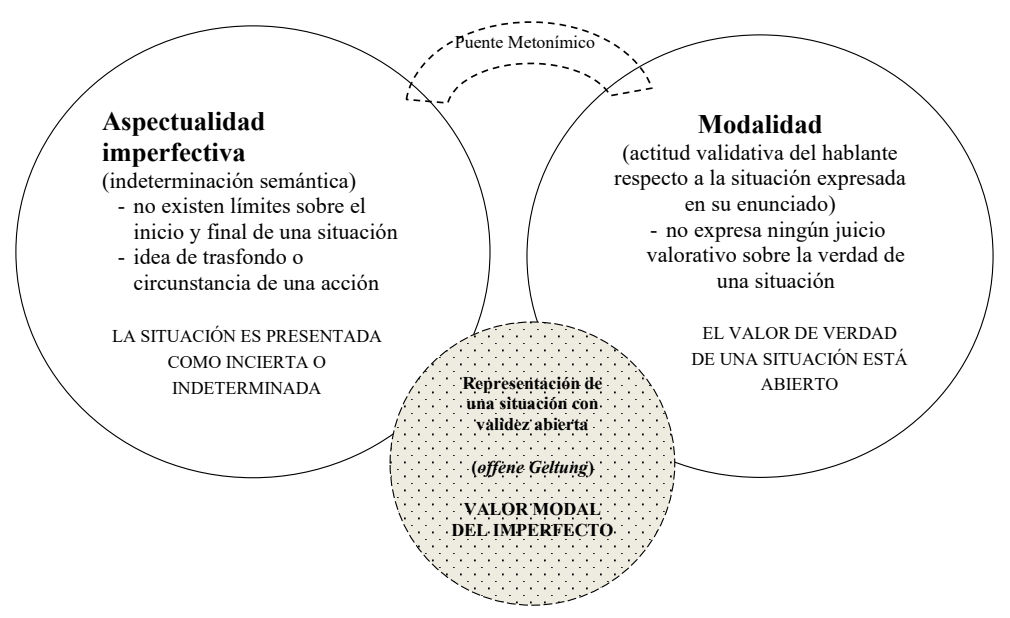

Cuadro 1. 'Puente metonímico': De la aspectualidad imperfectiva a la modalidad del pretérito imperfecto

\author{
3. EL PRETÉRITO IMPERFECTO \\ Y LA MODALIDAD Y EVIDENCIALIDAD
}

\title{
3.1. MODALIDAD Y MODALIDAD EPISTÉMICA
}

La modalidad es una supra categoría lingüística de dominio semántico y funcional que está relacionada con la opinión o actitud del hablante frente a la proposición de su enunciado o frente a la situación que es expresada en su enunciado (cf. Lyons 1977: 452) y se vale de diversos medios que existen en una lengua para su expresión. Por ejemplo, la modalidad es expresada morfológica y sintácticamente en forma léxica o mediante la entonación. Bybee y Fleischmann (1995: 2) se refieren a la 'modalidad' como:

The semantic domain pertaining to elements of meaning that languages express. It covers a broad range of semantic nuances-jussive, desiderative, intentive, hypothetical, potential, obligative, dubitative, hortatory, exclamative, etc. whose common denominator is the addition of a supplement or overlay of meaning to the most neutral semantic value of the proposition of an utterance, namely factual and declarative. 
Por su lado, Volkmann (2005: 59) se refiere a la modalidad como una categoría lingüística definida con frecuencia como "[...] die ausgedrückte Einstellung des Sprechers zum Gesagten [...]" ('[...] la actitud expresada del hablante frente a lo dicho [...]'). La actitud del hablante está relacionada con su evaluación y valoración subjetiva (cf. Volkmann 2005: 59-60). Existe la posibilidad de que el hablante exprese: a) cómo estima o cómo valora la situación expresada en el enunciado (actitud validativa), por ejemplo:

(10) El romance parece que va en serio, o por lo menos en lo que a él concierne [...] (CREA, El País, 04/07/1997, Actualidad)

o b) cómo se encuentra emocionalmente respecto a la realidad expresada, es decir, cómo evalúa la situación, si la evalúa positiva o negativamente (actitud evaluativa), como por ejemplo:

(11) Lamento no haber recibido la misma comprensión por parte de algunos compañeros. (CREA, La Vanguardia, 28/04/1995, Empleo, trabajo)

La actitud validativa (subjetiva) del hablante frente al contenido de un enunciado implica una cierta relatividad epistémica orientada con la conciencia del hablante y su evaluación sobre el contenido de lo dicho (cf. Volkmann 2005: 51). Así, la modalidad con respecto a la actitud validativa está asociada con tres posibilidades de factualidad (cf. Volkmann 2005: 57):

a) Factual (verdadera-aserción-válida): Ana está en casa.

b) Contrafactual (negación-no-válida): Ana no está en casa.

c) No-factual (probable, improbable, el 'valor de verdad' sobre el contenido del enunciado queda sin validar): Pepe dice que Ana está en casa.

Para fines de este estudio, se entenderá por 'modalidad' la representación de una situación con validez abierta o la evaluación del hablante sobre la verdad de una situación (cf. Volkmann 2005: 71). La actitud validativa, se expresa, por lo general, en situaciones representadas con offene Geltung ('validez abierta') (cf. Volkmann 2005: 60), lo que Dietrich (1992: 24) llama en alemán la Darstellung eines Sachverhalts mit offener Geltung (nichtfaktiv) ('representación de una situación con validez abierta (no-factual)'), como por ejemplo en:

(12) Vielleicht kommt (3RA.PERSON.SING.IND) er. ('Quizá viene (3RA.PERSON.SING.IND) él'). Quizá venga. 
Entre los tipos de modalidad existentes se encuentran, entre otras, la modalidad epistémica y deóntica ${ }^{5}$ :

La modalidad epistémica es una modalidad orientada al hablante, que se presenta vinculada a las nociones del conocimiento y creencia. Se define como la expresión del grado de compromiso que el hablante asume con respecto a la verdad de la proposición. La modalidad deóntica aporta, como la epistémica, una calificación de las condiciones en que se establece la verdad del predicado, que tampoco es simplemente aseverado o factual; pero, a diferencia de la anterior, supone una formulación de estas condiciones como pertenecientes a un sistema normativo en el que actúa bien el agente de la proposición, o bien directamente el hablante. $\mathrm{La}$ modalidad deóntica se llama también orientada hacia el agente (Haßler 2008: 160$)^{6}$.

El tipo de modalidad que se tratará en este trabajo es la modalidad epistémica, tal y como se ha mencionado anteriormente, ya que se parte de la premisa de que el pretérito imperfecto hace referencia implícita a la actitud epistémica del hablante con respecto al grado de certeza o compromiso que tiene sobre su enunciado. La modalidad epistémica está orientada hacia el hablante y contiene las nociones de posibilidad respecto a la verdad de la proposición sobre la base del conocimiento o creencia sobre una situación (cf. Lyons 1977: 793, Bybee y Fleischmann 1995: 4-6). En otras palabras, las "circunstancias del creer o conocer" respecto a algo (Volkmann 2005: 66) y "el grado de compromiso que tiene el hablante hacia lo que dice" (Palmer 1986: 51; también Bybee y Fleischmann 1995: 4 y Rojo y Veiga 1999: 3214, entre otros). En el inglés (y en otras lenguas), los adverbios y adjetivos modales permiten una expresión directa de las actitudes del hablante con respecto a la certeza, probabilidad y posibilidad (cf. Nuyts 2005: 10-11). Por ejemplo, en inglés, la modalidad epistémica con respecto al 'grado de probabilidad' sobre un hecho es expresada por maybe (cf. ejemplo 13), y parafraseando la podemos encontrar también en el uso del pretérito imperfecto pagaba en el ejemplo (14):

(13) John isn't home yet - well, maybe he missed the bus. (Nuyts 2005: 10)

\footnotetext{
5 Para más detalles, sobre los tipos de modalidad, por ejemplo, modalidad alética (o de necesidad), cf. Dietrich (1992: 45 y ss.), Volkmann (2005: 66-67), Haßler (2016: 299-315), entre otros.

6 El subrayado es mío.
} 
('Juan todavía no está en casa - bueno, probablemente perdió el bus').

(14) Se pagaba los viajes. La tirantez llegó a extremos insospechados. (CREA, El País, 02/06/1984, Deportes)

Probablemente, se pagaba los viajes. (Esto es incierto o no se puede afirmar con toda seguridad).

El grado de certeza, probabilidad o compromiso está relacionado con las circunstancias del creer o del conocer un hecho o una situación, es decir, con los 'conocimientos (generales) cognitivos' que el hablante tenga sobre (la percepción de) una realidad y con su juicio validativo y subjetivo de ella. De esa forma, si las circunstancias del creer o del conocer del hablante respecto a un hecho o una realidad se encuentran limitadas o supeditadas por diversas razones, ya sea que el hablante tenga acceso directo a la información o haya recibido la información por 'otras fuentes', esto determinará su postura o actitud al momento de expresar su propio enunciado. Si no se siente seguro de lo que informa, se distanciará de su enunciado y se limitará a reproducir solo lo que le dijeron o escuchó. Así, en el siguiente ejemplo:

(15) La Feria del Mueble antiguo se clausuraba hoy, ¿no? (Gutiérrez Aráus 1995b: 179)

el hablante expresa su incertidumbre sobre la situación porque al parecer desconoce o no cuenta con una evidencia directa de la información: Alguien me dijo que la Feria del Mueble antiguo se [clausuraba] clausura hoy [...]. Lo mismo ocurre en el siguiente ejemplo:

(16) En otro atentado con coche bomba, en la ciudad de Musayib, a unos 30 kilómetros de Hilla, moría un agente de policía y otras dos personas resultaban heridas. (CREA, El Mundo, 01/03/2005, Internacional)

Mediante el uso de los pretéritos imperfectos moría y resultaban (cf. ejemplo 16) se restringe la validez o el valor de verdad de la situación expresada y la situación se presenta con offene Geltung ('validez abierta'). El grado de certeza del contenido de ambos enunciados (cf. ejemplos 15-16) es bajo, a diferencia del contenido de un enunciado expresado en pretérito perfecto simple, donde el grado de certeza parece ser más alto porque excluye toda consideración de validez abierta:

(17) Otro supuesto miembro del IRA murió por disparos de los agentes. (CREA, El Diario Vasco, 24/09/1996, Política) 
(18) Gutiérrez Mellado, el conductor y el escolta, ambos policías, resultaron heridos en el siniestro. (CREA, La Vanguardia, 16/12/1995, Política)

En el ejemplo (16), mediante los pretéritos imperfectos moría y resultaban el hablante parece, entonces, no asumir la veracidad o falsedad del contenido de su enunciado, por lo que abre las posibilidades de interpretar la información como especulación, sospecha o duda de lo dicho. En el español, los verbos creer, suponer, dudar, entre otros, expresan la actitud validativa, es decir, el grado de certeza del hablante con respecto a la veracidad de su enunciado. En algunos ejemplos del CREA, el pretérito imperfecto también puede llevar implícito estos significados semánticos (de creencia, sospecha y duda). En el siguiente ejemplo, el contexto nos indica que el hablante usa el pretérito imperfecto para referirse a una suposición (al parecer salía de su domicilio) hecha en base a lo que oyó o le dijeron al hablante:

(19) Algunos vecinos del inmueble en el que residía la mujer señalaron que la vieron por última vez en la tarde del lunes. La víctima mantenía escasas relaciones con el resto del vecindario y al parecer apenas salía de su domicilio, que estaba situado en el quinto piso del número 1 de la calle Montico, en el barrio de San Lázaro. (CREA, El Mundo, 24/08/1994, Actualidad)

El hablante, entonces, no expresa ningún juicio respecto a la verdad de la situación expresada en el enunciado, y esto puede estar relacionado con el modo de acceso a la información, es decir, de cómo se obtuvo o se adquirió dicho conocimiento sobre la situación (evidencialidad), lo que será explicado a continuación.

\subsection{EVIDENCIALIDAD Y EVIDENCIALIDAD INDIRECTA}

La validación del enunciado (juicio epistémico) está basado en la 'evidencia' que tiene un hablante para expresar su información, es decir, en cómo obtuvo la información. La 'evidencia' es la que tiene que ver con el origen de la fuente de información, es decir, con la evidencialidad. Volkmann (2005: 75) postula que la evidencialidad se refiere a la fuente de la cual el hablante ha obtenido su información. Existen lenguas, como Tuyuca ${ }^{7}$, donde los afijos y

\footnotetext{
Tuyuca es una de las lenguas indígenas de habla oral en Colombia y Brasil. Esta lengua está marcada evidencialmente por partículas gramaticales obligatorias.
} 
morfemas flexivos muestran cómo se ha obtenido cierta información, como lo muestra el ejemplo de Barnes (1984: 257) ${ }^{8}$ :

(1) díiga apé-wi Él jugaba al fútbol’ (vi que jugaba)

(2) díiga apé-ti ‘Él jugaba al fúbol’ (escuché que jugaba) pero no lo vi)

(3) díiga apé-yigi 'Él jugaba fútbol'

(4) díiga apé-yi 'Él jugaba fútbol'

(5) díiga apé-hĩyi 'Él jugaba fútbol' (alguien me contó)

(yo veo/tengo indicios)

(es razonable) visual

non-visual

(other senses)

secondhand

apparent

assumed

De acuerdo a Willet (1988: 57) existen dos tipos de evidencia: la evidencia directa e indirecta. En la evidencia directa el hablante es testigo propio de los eventos o los hechos que quiere informar o reportar en su enunciado, ya sea que haya visto (visualmente), haya escuchado (acústicamente), pero estando presente, o haya percibido el hecho mediante alguno de sus otros sentidos. En la evidencia indirecta no existe este contacto directo con el evento o el hecho del cual se quiere informar. La evidencia indirecta se subclasifica en a) referida (reportada) cuando la información adquirida por el hablante es de segunda o tercera mano o de folclore (saber popular o conocimiento general), o por hearsay (fuentes ajenas o externas) e b) inferida cuando "el hablante no tiene acceso directo a la situación descrita pero sí tiene contacto directo con huellas o rastros de esa situación que le permiten inferir lo que ocurre o ha ocurrido (inferencia) o conoce algo que le permite deducir que es probable que la situación se dé o se haya dado (razonamiento)"' (Wachtmeister Bermúdez 2005: 7). Willet representa de esta forma los tipos de evidencia:

Cf. también Volkmann (2005: 81).

Por ejemplo, cuando el hablante infiere una situación y lo expresa como: “iestán en casa!" porque ve que la luz de la casa está encendida, y cuando dice algo por razonamiento "va a empezar tu programa favorito [porque son las 7:29 y tu programa empieza 7:30]" (Wachtmeister Bermúdez 2005: 7). 


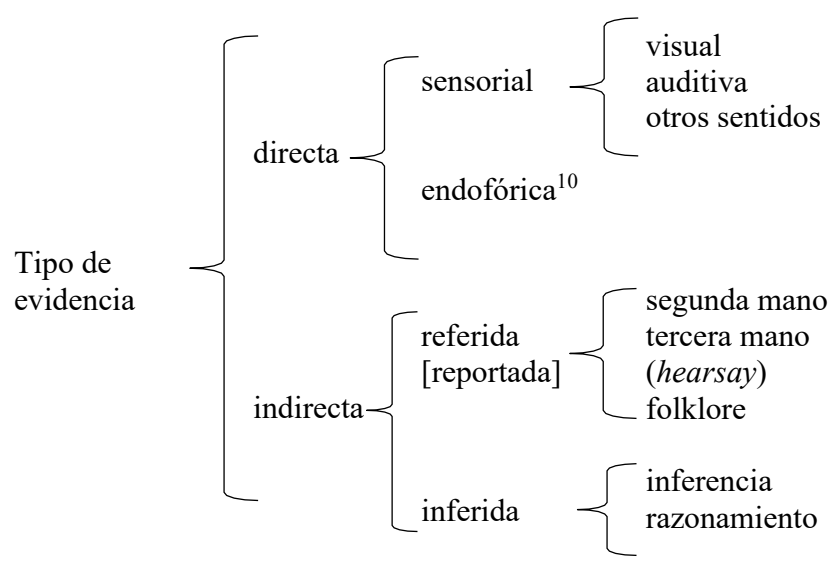

Cuadro 2. Tipos de evidencia según Willet (1988: 57)

Las lenguas, como el español, que no poseen 'evidenciales propios' (cf. los evidenciales del (1-5) de la lengua Tuyuca) se valen de otros medios lingüísticos para expresar el tipo de evidencia de una información. Esta función la asumen, por ejemplo, los marcadores evidenciales -que son medios de expresión gramaticales o léxicos e indican el tipo de la fuente de información en un enunciado, como por ejemplo: seguramente, aparentemente, al parecer y otros medios que no están o están parcialmente gramaticalizados. Por ejemplo, el futuro sintético también ha asumido la función de un marcador evidencial porque se usa más para expresar valores modales y evidenciales que temporales: En cuanto a su valor temporal, el 'futuro sintético' se ha vuelto muy inestable y redundante (cf. Haßler 1997: 42).

El tipo de evidencialidad que se tratará en este estudio es la evidencialidad indirecta (transmitida o reportada), puesto que el pretérito imperfecto puede hacer una referencia implícita a una fuente externa de información, tal y como lo ha indicado Reyes (1990) con el "imperfecto oblicuo" o "citativo" (Reyes 1990: 28) que equivale a decir "tal fuente informó" (Reyes 1990: 32), con el que se trata de deslindar responsabilidades: "el hablante no asume enteramente lo que dice, y para eso indica (por ejemplo, usando el imperfecto de ese modo peculiar) que su conocimiento procede del testimonio de otro" (Reyes 1994: 12), como por ejemplo en:

(20) Mañana daba una conferencia María.

"El uso, aparentemente anómalo, del imperfecto daba para hacer una referencia al futuro se debe a la intención del hablante de señalar que 
su información es de segunda mano: se puede agregar fácilmente una expresión citativa como según me dijeron. [...]”. (Reyes 1994: 12)

En los siguientes ejemplos (21-22) también podemos encontrar claramente la función evidencial transmitida o reportada del pretérito imperfecto, donde el hablante parece distanciarse del contenido de sus enunciados por tratarse de una información adquirida por terceras fuentes:

(21) Jesús G.C., vecino de Vigo de 88 años de edad, moría ayer por la mañana tras ser arrollado por un camión en un paso de peatones de la avenida de A Florida. (CREA, Faro de Vigo, 22/11/2002, Actualidad)

(22) Al día siguiente de aparecer en las páginas de este diario un artículo suyo sobre la situación de la Universidad, el director del Colegio Mayor Diego de Covarrubias, Diego Mateo del Peral, recibía un oficio del rector de la Universidad Complutense de Madrid en el cual le comunicaba que había propuesto su cese inmediato a la junta de gobierno de la referida universidad. (CREA, El Pais, 04/08/1997, Educación)

El uso del pretérito imperfecto en ambos enunciados anteriores (21-22) hace que el carácter asertativo del enunciado citador sea relativamente más débil. No obstante, no siempre un marcador evidencial llevará implícito el grado de compromiso de la verdad de un enunciado. En los enunciados anteriores (21-22) no se trata de que el hablante (periodista) desconoce o no está seguro de lo que informa, ya que puede ser que esta información sea de conocimiento general de todos (saber popular), sino que su actitud es de distanciamiento porque el locutor se limita a reproducir lo que escuchó, ya sea por discreción, reserva o imparcialidad. En el siguiente enunciado (23) la función evidencial reportada del pretérito imperfecto está explícitamente marcada o viene introducida por según:

(23) Goteborg-Bayern.- "El peor Bayern de Munich de todos los tiempos", según escribía el pasado domingo el propio Franz Beckenbauer, hoy presidente, llegó ayer a Suecia para resolver su eliminatoria frente al Goteborg (18:45 h. La 2) [...] (CREA, El Mundo, Deportes, 15/03/1995)

Entonces, "la indicación de la fuente de la información puede implicar un grado de fiabilidad de la información, pero no necesariamente" (Haßler 2008: 165). No obstante, cabe mencionar que la evidencia por hearsay (evidencia transmitida o reportada) es considerada como menos confiable que la evidencia directa percibida visualmente (cf. Givón 1982). De este modo, se puede afirmar que el pretérito imperfecto asume una función evidencial 
de tipo transmitida o reportada, por medio de la cual no solo codifica o hace referencia implícita a una fuente externa de información, sino que también asume la función de un elemento modal mediante el cual codifica el grado de compromiso del hablante (Regresspflicht 'obligación de recurso o grado') y el grado de certeza que tiene el hablante sobre el contenido de su enunciado, mostrando distanciamiento: "el locutor ofrece una determinada información y a su vez califica la validez de tal información que tiene para sí mismo en términos de evidencia que posee" (cf. Palmer 1986: 54). En el siguiente enunciado el juicio validativo o el valor de verdad de la situación expresada en el enunciado está abierto:

(24) Un soldado croata disparaba ayer con antiaéreos contra posiciones terrestres serbias situadas a 200 metros. (CREA, La Vanguardia, 02/05/1995, Ciencia Militar)

Se puede observar de este modo que el valor evidencial del pretérito imperfecto está relacionado con su valor epistémico (cf. Haßler 2008: 233).

\section{METODOLOGÍA DE ANÁLISIS}

El análisis del corpus es cuantitativo, pero también mediante algunos ejemplos representativos se analizará y explicará la función modal y evidencial del pretérito imperfecto en determinados contextos periodísticos (análisis cualitativo). En el análisis cuantitativo se muestran a) datos estadísticos sobre la frecuencia total en que aparecen los verbos seleccionados en pretérito imperfecto en los respectivos rubros periodísticos ('hacienda y economía', 'negocios', 'política', 'actualidad' y 'deportes') del corpus en línea CREA (Corpus de la Real Academia Española) del español peninsular. Asimismo, b) se distingue entre el uso normal o prototípico (funciones primarias: temporal $\mathrm{y}$ aspectual $={ }^{\circ} \mathrm{T} \& \mathrm{~A}$ ') y el uso no-prototípico (funciones secundarias: modal y evidencial $=$ ' $M$ \& E') del pretérito imperfecto. También c) se mostrará la frecuencia de casos en los que el pretérito imperfecto puede asumir su función modal y evidencial, marcando la actitud epistémica del hablante y haciendo referencia implícita a una fuente externa de información. Se han escogido los verbos reconocer, ascender, pagar, morir y estallar, entre otros, ya que por su naturaleza léxica llevan una marca de límite temporal interno y sus usos son más normales en la forma perfectiva (pretérito perfecto simple) que la imperfectiva (pretérito imperfecto). En detalle, en este análisis cuantitativo (y 
cualitativo) se mostrarán los casos en los que el pretérito imperfecto asume una función modal y evidencial y se responderá a la pregunta si el pretérito imperfecto puede asumir por sí solo estas funciones o qué factores léxicosemánticos y contextuales aportan con el significado modal y evidencial del pretérito imperfecto. Asimismo, se observará la actitud del hablante frente a lo que dice. Los ejemplos que nos interesan en este estudio son aquellos en los cuales el pretérito imperfecto pueda indicar modalidad epistémica y evidencialidad indirecta cuando aparezca como núcleo principal del predicado (cf. ejemplos 25-26) y no necesite ser introducido por un marcador evidencial explícito (cf. 27-28):

(25) La Fira no pagaba alquiler alguno y se comprometió a dedicar un tercio de sus ingresos brutos a mejorar el patrimonio. (CREA, $L a$ Vanguardia, 25/01/1994, Economía y Hacienda)

(26) El propio Kok lo reconocía: "Hemos ganado pero hemos perdido". Con ello hacía referencia al fuerte descenso de apoyo que han registrado aun cuando su descalabro haya sido menor que el del CDA. (CREA, El Mundo, 04/05/1994, Política)

(27) Según la Fiscalía milanesa, el magistrado romano hacía favores "a un potente empresario de Milán" que le pagaba con "dinero negro". (CREA, El Mundo, 15/03/1996, Política)

(28) Según esta documentación de la Central de Información de Riesgos (CIR) del Banco de España, la deuda del PP ascendía en junio de 1994 a 3.419 millones de pesetas, de los cuales 1.742 eran en créditos financieros con un plazo de hasta un año y 1.677 en créditos a más de un año. (CREA, La Vanguardia, 03/12/1994, Economía y Hacienda)

Se considerarán entonces solo los casos (como los ejemplos 25 y 26) en los cuales el pretérito imperfecto aparece como núcleo principal del enunciado y no hay ninguna especificación sobre la fuente de información. No obstante, en el análisis cuantitativo se compararán los casos en los que el pretérito imperfecto asume la función modal y evidencial en forma independiente o cuando está explícita mediante algunos marcadores epistémicos-evidenciales para determinar si hay alguna razón por parte del hablante (periodista) para (no) mencionar la fuente de información. 


\section{ANÁLISIS Y RESULTADOS DEL CORPUS: LA FUNCIÓN MODAL Y EVIDENCIAL DEL PRETÉRITO IMPERFECTO ${ }^{10}$}

Entre los verbos puntuales y perfectivos analizados (reconocer, ascender, pagar, morir y estallar) que aparecen en pretérito imperfecto en la sección 'periódicos' en los respectivos rubros periodísticos en el corpus del CREA, del español penínsular, se puede observar que el uso más frecuente de estos verbos en pretérito imperfecto es reconocía, sobre todo, en la sección 'política':

\begin{tabular}{|l|c|c|c|c|c|c|}
\cline { 2 - 8 } \multicolumn{1}{l|}{} & \multicolumn{5}{l}{ VERBOS (FRECUENCIA TOTAL DE CASOS) } \\
\hline $\begin{array}{l}\text { CREA / PERIÓDICOS } \\
\text { SECCIONES ANALIZADAS } \\
\text { (ESPAÑOL PENINSULAR) }\end{array}$ & reconocía & ascendía & pagaba & moría & estallaba & TOTAL \\
\hline ECONOMÍA Y HACIENDA & $3 \%$ & $6 \%$ & $3 \%$ & $0,5 \%$ & $0 \%$ & $12,5 \%$ \\
\hline NEGOCIOS & $2 \%$ & $4 \%$ & $3 \%$ & $0,5 \%$ & $0 \%$ & $9,5 \%$ \\
\hline POLÍTICA & $26 \%$ & $3 \%$ & $8 \%$ & $2 \%$ & $3 \%$ & $42 \%$ \\
\hline ACTUALIDAD & $7 \%$ & $2 \%$ & $4 \%$ & $5 \%$ & $1 \%$ & $19 \%$ \\
\hline DEPORTES & $8 \%$ & $3 \%$ & $3 \%$ & $3 \%$ & $0 \%$ & $17 \%$ \\
\hline TOTAL & $46 \%$ & $18 \%$ & $21 \%$ & $11 \%$ & $4 \%$ & $100 \%$ \\
\hline
\end{tabular}

Tabla 1. Frecuencia y uso del pretérito imperfecto en las respectivas secciones periodísticas ${ }^{11}$

En la mayoría de los casos de reconocía se trata de que el hablante acepta y admite la declaración que ha hecho o la realidad de lo que dice o sucede, como por ejemplo:

10 Para facilitar la lectura y el análisis por parte del lector se muestran en porcentajes las veces o la frecuencia en que el pretérito imperfecto aparece en las determinadas secciones periodísticas del español peninsular en CREA.

${ }^{11}$ El total de casos del pretérito imperfecto encontrados en CREA en todas las secciones periodísticas aquí mencionadas son 291 que equivale al 100\%. De este número total de casos (291 al 100\%) se calcula respectivamente el porcentaje de los casos en que aparece reconocía, ascendia, pagaba, moría y estallaba en cada sección periodística. 
(29) El presidente del PP reconocía el "interés que desde hace mucho tiempo tenía por conocer y seguir la ruta del escritor Josep Pla" y no escondía su satisfacción por "haberlo podido hacer ahora, acompañado por unos buenos amigos y de la manera discreta que yo siempre había deseado hacer esta visita". (CREA, La Vanguardia, 30/10/1995, Política)

(30) El momento es delicado. Así lo reconocía ayer el presidente Yasir Arafat en un discurso, retransmitido por teléfono, que llegó a las juventudes de Belén que se manifestaban por las calles. (CREA, El País, 24/09/2002, Política)

Con respecto a los usos de ascendía, se usa más en contextos de 'economía y hacienda' y 'negocios', mientras que los usos de pagaba es mucho más frecuente en la sección 'política'. Obsérvense algunos ejemplos:

(31) La cartera de préstamos del crédito oficial ascendía, a finales de junio, a 1.340.614 millones de pesetas, cifra que representa una tasa de crecimiento interanual del crédito oficial del 22,2\%. (CREA, El País, 02/08/1980, Economía y Hacienda)

(32) $[\ldots]$ No era fácil imaginarlo. ¿Pero quiere saber otra cosa que muy pocos conocen? He sido un inquilino del PCI. Mi padre pagaba el alquiler al dueño comunista de la casa donde vivíamos, quien, por otra parte, fue un excelente casero. (CREA, El Mundo, 20/04/1996, Política)

Los usos del pretérito imperfecto son muy pocos con estallaba y moría en comparación con los otros verbos. Esto confirma que los usos del verbo morir y estallar en la forma imperfectiva (moría y estallaba) son mucho más inusuales que los otros verbos en pretérito imperfecto, pero también en comparación con su uso en la forma perfectiva, tal y como se muestra en esta tabla (2):

\begin{tabular}{|l|c|c|c|c|c|}
\cline { 2 - 6 } \multicolumn{1}{c|}{} & \multicolumn{4}{c|}{ VERBOS (FRECUENCIA TOTAL DE CASOS) } \\
\hline $\begin{array}{l}\text { CREA / PERIÓDICOS } \\
\text { SECCIONES ANALIZADAS } \\
\text { (ESPAÑOL PENINSULAR) }\end{array}$ & reconoció & ascendió & pagó & murió & estalló \\
\hline ECONOMÍA Y HACIENDA & $10 \%$ & $32 \%$ & $7 \%$ & $1 \%$ & $5 \%$ \\
\hline NEGOCIOS & $4 \%$ & $26 \%$ & $18 \%$ & $1 \%$ & $2 \%$ \\
\hline POLÍTICA & $49 \%$ & $15 \%$ & $35 \%$ & $36 \%$ & $54 \%$ \\
\hline
\end{tabular}




\begin{tabular}{|l|c|c|c|c|c|}
\hline ACTUALIDAD & $10 \%$ & $7 \%$ & $10 \%$ & $52 \%$ & $27 \%$ \\
\hline DEPORTES & $27 \%$ & $20 \%$ & $30 \%$ & $10 \%$ & $12 \%$ \\
\hline TOTAL & $100 \%$ & $100 \%$ & $100 \%$ & $100 \%$ & $100 \%$ \\
\hline
\end{tabular}

Tabla 2. Frecuencia y uso de los verbos reconocer, ascender, pagar, morir y estallar en el pretérito perfecto simple en las respectivas secciones periodísticas ${ }^{12}$

En las siguientes tablas (3a) y (3b) se hace la distinción entre el uso normal o prototípico: (función temporal-aspectual ' $\mathrm{T} \& \mathrm{~A}$ ') y no prototípico (función modal y evidencial ' $\mathrm{M} \& \mathrm{E}$ ') del pretérito imperfecto:

\begin{tabular}{|c|c|c|c|c|c|c|c|c|c|}
\hline \multirow{3}{*}{$\begin{array}{l}\text { CREA } \\
\text { (PERIÓDICOS) } \\
\text { SECCIONES }\end{array}$} & \multicolumn{9}{|c|}{ VERBOS } \\
\hline & \multicolumn{3}{|c|}{ reconocía } & \multicolumn{3}{|c|}{ ascendia } & \multicolumn{3}{|c|}{ pagaba } \\
\hline & TOTAL & $\mathrm{T} \& \mathrm{~A}$ & $\mathbf{M} \& \mathbf{E}$ & TOTAL & $\mathrm{T} \& \mathrm{~A}$ & $\mathbf{M} \& \mathbf{E}$ & TOTAL & $\mathrm{T} \& \mathrm{~A}$ & $\mathbf{M} \& \mathbf{E}$ \\
\hline $\begin{array}{l}\text { ECONOMÍA Y } \\
\text { HACIENDA }\end{array}$ & $3 \%$ & $0,3 \%$ & $2,7 \%$ & $6 \%$ & $1 \%$ & $5 \%$ & $3 \%$ & $1,5 \%$ & $1,5 \%$ \\
\hline NEGOCIOS & $2 \%$ & $0,6 \%$ & $1,4 \%$ & $4 \%$ & $1 \%$ & $3 \%$ & $3 \%$ & $1 \%$ & $2 \%$ \\
\hline POLÍTICA & $26 \%$ & $10 \%$ & $16 \%$ & $3 \%$ & $1 \%$ & $2 \%$ & $8 \%$ & $4,2 \%$ & $3,8 \%$ \\
\hline ACTUALIDAD & $7 \%$ & $3,4 \%$ & $3,6 \%$ & $2 \%$ & $1,7 \%$ & $0,3 \%$ & $4 \%$ & $1,8 \%$ & $2,2 \%$ \\
\hline DEPORTES & $8 \%$ & $0,7 \%$ & $7,3 \%$ & $3 \%$ & $2 \%$ & $1 \%$ & $3 \%$ & $1 \%$ & $2 \%$ \\
\hline TOTAL & $46 \%$ & $15 \%$ & $31 \%$ & $18 \%$ & $6,7 \%$ & $11,3 \%$ & $21 \%$ & $9,5 \%$ & $11,5 \%$ \\
\hline
\end{tabular}

Tabla 3a. Frecuencia del uso temporal-aspectual (T \& A) y modal-evidencial (M \& E) de reconocía, ascendía y pagaba

12 El $100 \%$ en cada columna de los verbos perfectivos equivale al número total de casos que aparece el pretérito perfecto simple en todas las secciones periodísticas, a saber: reconoció 1228 casos, ascendió 157 casos, pagó 327 casos, murió 652 casos y estalló 214 casos. De este total de casos de cada columna se calcula el porcentaje respectivo de los números de casos en que aparece el pretérito perfecto simple en cada sección periodística. 


\begin{tabular}{|l|c|c|c|c|c|c|}
\hline \multirow{2}{*}{$\begin{array}{l}\text { CREA } \\
\text { (PERIÓDICOS) }\end{array}$} & \multicolumn{5}{|c|}{ verbos } \\
\cline { 2 - 7 } & \multicolumn{3}{|c|}{ moría } & & & \\
\hline \multirow{2}{*}{ SECCIONES } & TOTAL & T \& A & M \& E & TOTAL & T \& A & M \& E \\
\hline ECONOMÍA Y HACIENDA & $0,5 \%$ & $0 \%$ & $\mathbf{0 , 5} \%$ & $0 \%$ & $0 \%$ & $\mathbf{0 \%}$ \\
\hline NEGOCIOS & $0,5 \%$ & $0,5 \%$ & $\mathbf{0 \%}$ & $0 \%$ & $0 \%$ & $\mathbf{0} \%$ \\
\hline POLÍTICA & $2 \%$ & $0,8 \%$ & $\mathbf{1 , 2} \%$ & $3 \%$ & $1 \%$ & $\mathbf{2 \%}$ \\
\hline ACTUALIDAD & $5 \%$ & $1 \%$ & $\mathbf{4 \%}$ & $1 \%$ & $0,5 \%$ & $\mathbf{0 , 5} \%$ \\
\hline DEPORTES & $3 \%$ & $2,7 \%$ & $\mathbf{0 , 3} \%$ & $0 \%$ & $0 \%$ & $\mathbf{0} \%$ \\
\hline TOTAL & $11 \%$ & $5 \%$ & $\mathbf{6 \%}$ & $4 \%$ & $1,5 \%$ & $\mathbf{2 , 5} \%$ \\
\hline
\end{tabular}

Tabla 3b. Frecuencia del uso temporal-aspectual (T \& A) y modal-evidencial (M \& E) de moría y estallaba

En los usos normales ( $\mathrm{T} \& \mathrm{~A}$ ), el pretérito imperfecto expresa a) su valor temporal relativo cuando aparece anclado o subordinado a otras situaciones del pasado (cf. ejemplos 33-34) o expresa simultaneidad en el pasado (cf. ejemplo 35) y b) su valor aspectual imperfectivo cuando describe una acción en desarrollo, en transcurso o presenta una acción como continua, progresiva o habitual (cf. ejemplos 36-37):

(33) El artefacto, colocado bajo el asiento del conductor, estalló sobre las 14,15 horas, cuando Leceta ascendía la rampa del garaje para, según algunas fuentes, llevar el turismo a una revisión. (CREA, El Mundo, 20/06/1996, Política)

(34) La alarma fue dada por un vecino que vio cómo la aeronave estallaba en llamas y llamó a los bomberos. (CREA, $A B C, 05 / 05 / 1989$, Actualidad)

(35) Mientras reconocía que CiU "ha conseguido un millón de votos y no se puede menospreciar" a la vez que reivindicaba que "se ha acabado el tiempo en que había que había quien daba patentes de catalanidad". (CREA, La Razón Digital, 16/12/2003, Política)

(36) Aquí, en España, hace unos años, teníamos los pagarés del Tesoro, que llegaron a embalsar más de tres billones de pesetas de dinero negro, a los que se les pagaba una rentabilidad muy baja a cambio de la opacidad fiscal. (CREA, La Vanguardia, 03/04/1995, Política) 
(37) [C]uando moría el titular su familia se reunía y facilitaba al presidente del banco el nombre del candidato a sucederle. (CREA, El Pais, 02/06/1989, Negocios)

En su función modal y evidencial, el pretérito imperfecto aparece como el elemento sintáctico principal en el enunciado, es decir, no aparece subordinado a ningún elemento oracional ni tampoco anclado a otra situación del pasado. Obsérvense los siguientes ejemplos:

(38) A esa misma hora, en la A-7 a su paso por la Amposta (Tarragona) una mujer argelina llamada Noura Mezine, de 31 años, moría al chocar su coche contra una barra de protección. (CREA, $A B C$ Electrónico, 26/08/1997, Actualidad)

(39) En total, al finalizar el año 1981 eran 34 los Bancos españoles que tenían abiertas oficinas en el extranjero. El número total de oficinas operativas ascendía a 92 y el de oficinas de representación a 185 . (CREA, $A B C, 18 / 05 / 1982$, Negocios)

(40) La peseta, ante esta recuperación del marco, no hizo nada más que ceder terreno. Tras abrir a 92,3, al final se pagaba a 92,87. Operadores comentaban la posibilidad de que el Banco de España hubiese intervenido, aunque con escasos resultados. (CREA, La Vanguardia, 30/03/1995, Negocios)

(41) En las acciones del club, emitidas en 1973, el nominal ascendía a 10.000 pesetas. (CREA, El País, 02/02/1977, Deportes)

(42) En el período Urralburu se gastaron más de 50.000 millones de pesetas. Empresas como Huarte pagaba comisiones para conseguir la adjudicación. Roldán llevaba las cuentas en Suiza y anotaba meticulosamente las iniciales de los que cobraban esas comisiones [...] (CREA, El Mundo, 03/12/1995, Política)

En todos los ejemplos anteriores (38-42), por medio del pretérito imperfecto, el hablante (periodista) se limita a reproducir la información sin especificar o indicar de dónde obtuvo la información. Parece ser que no es importante mencionar la fuente de información, ya sea porque el hablante desconoce la fuente o simplemente porque no quiere mencionarla, distanciándose así del contenido de su enunciado y no asumiendo el grado de compromiso (Regresspflicht 'obligación de recurso') de lo que dice. El uso modal y evidencial del pretérito imperfecto relacionado con el distanciamiento y la falta de compromiso en asumir la validez o la veracidad del contenido de un enunciado es confirmado también por Haßler (2012: 147) al señalar que 
el pretérito imperfecto se usa aún mucho más cuando se trata de cifras y números en reportes de bolsa ${ }^{13}$.

A continuación, en las tablas (4a) y (4b), se hace una recopilación de la función modal y evidencial de los verbos respectivos en pretérito imperfecto:

\begin{tabular}{|c|c|c|c|c|c|c|}
\hline \multirow{2}{*}{$\begin{array}{l}\text { CREA (PERIÓDICOS) } \\
\text { SECCIONES } \\
\end{array}$} & \multicolumn{2}{|c|}{ reconocía } & \multicolumn{2}{|c|}{ ascendia } & \multicolumn{2}{|c|}{ pagaba } \\
\hline & TOTAL & $\mathbf{M} \& \mathbf{E}$ & TOTAL & $\mathbf{M} \& \mathbf{E}$ & TOTAL & $\mathbf{M} \& \mathbf{E}$ \\
\hline ECONOMÍA Y HACIENDA & $3 \%$ & $2,7 \%$ & $6 \%$ & $5 \%$ & $3 \%$ & $1,5 \%$ \\
\hline NEGOCIOS & $2 \%$ & $1,4 \%$ & $4 \%$ & $3 \%$ & $3 \%$ & $2 \%$ \\
\hline POLÍTICA & $26 \%$ & $16 \%$ & $3 \%$ & $2 \%$ & $8 \%$ & $3,8 \%$ \\
\hline ACTUALIDAD & $7 \%$ & $3,6 \%$ & $2 \%$ & $0,3 \%$ & $4 \%$ & $2,2 \%$ \\
\hline DEPORTES & $8 \%$ & $7,3 \%$ & $3 \%$ & $1 \%$ & $3 \%$ & $2 \%$ \\
\hline TOTAL & $46 \%$ & $31 \%$ & $18 \%$ & $11,3 \%$ & $21 \%$ & $11,5 \%$ \\
\hline
\end{tabular}

Tabla 4a. Frecuencia sobre la función modal y evidencial de reconocía, ascendía y pagaba

\begin{tabular}{|l|c|c|c|c|}
\hline \multirow{2}{*}{ CREA (PERIÓDICOS) } & \multicolumn{4}{|c|}{ estallaba } \\
\cline { 2 - 5 } & \multicolumn{2}{|c|}{ moría } & \multicolumn{2}{|c|}{ M $\boldsymbol{E}$} \\
\hline SECCIONES & TOTAL & M \& E & TOTAL & M \\
\hline ECONOMÍA Y HACIENDA & $0,5 \%$ & $\mathbf{0 , 5} \%$ & $0 \%$ & $\mathbf{0 \%}$ \\
\hline NEGOCIOS & $0,5 \%$ & $\mathbf{0 \%}$ & $0 \%$ & $\mathbf{0 \%}$ \\
\hline POLÍTICA & $2 \%$ & $\mathbf{1 , 2} \%$ & $3 \%$ & $\mathbf{2 \%}$ \\
\hline ACTUALIDAD & $5 \%$ & $\mathbf{4 \%}$ & $1 \%$ & $\mathbf{0 , 5} \%$ \\
\hline DEPORTES & $3 \%$ & $\mathbf{0 , 3} \%$ & $0 \%$ & $\mathbf{0 \%}$ \\
\hline TOTAL & $11 \%$ & $\mathbf{6 \%}$ & $4 \%$ & $\mathbf{2 , 5 \%}$ \\
\hline
\end{tabular}

Tabla 4b. Frecuencia sobre la función modal y evidencial de moría y estallaba

En las tablas (4a) y (4b) se puede observar que los usos modales y evidenciales de reconocía son muchos más que con los otros verbos, sobre todo, en la

13 Sobre el uso sistemático del pretérito imperfecto en reportes financieros y de bolsa, cf. Böhm (2016: 530). 
sección 'política'. Estos usos están relacionados con la reproducción de enunciados dichos por otras personas, ya sean en forma de discurso directo (cf. ejemplo 43-44) o discurso indirecto (cf. ejemplo 45-46):

(43) 'Ahora he recuperado el ánimo para entrenar y jugar', reconocía el delantero. (CREA, Diario de Navarra, 29/04/1999, Deportes)

(44) "Pequeñas cosas que no tienen importancia y que al final importan mucho", reconocía Chabeli Iglesias cuando se separó de Ricardo Bofill. (CREA, El Mundo, 31/03/1996, Actualidad)

(45) El presidente del club aragonés, José Luis Rubio, reconocía ayer haber mantenido contactos con otros entrenadores para sustituir al norteamericano, lo que parece indicar que sus días están contados. (CREA, El País, 01/06/1984, Deportes)

(46) Ayer mismo, el secretario de Estado de Defensa y responsable máximo del tema de Irak, Fernando Díez Moreno, reconocía que la zona de despliegue "todavía no está determinada". (CREA, El País, 04/06/2003, Política)

En cuanto al uso modal y evidencial de ascendía, en todos los casos aparece el pretérito imperfecto introduciendo cifras o números en el contexto de reportes financieros, presupuestos, transferencias bancarias, mercados de bolsa y créditos, entre otros, como por ejemplo:

(47) La cifra global prevista ascendía a 967.0\% millones de pesetas, incluidos en los cuales está el Fondo de Acción Coyuntural, que viene incorporándose en los últimos Presupuestos Generales. (CREA, El País, 10/11/1976, Economía y Hacienda)

(48) En cuanto al valor de las instalaciones en explotación ascendía, al 30 de junio, a 1,25 billones de pesetas, y las inmovilizaciones en curso eran de 321.966 millones. (CREA, $A B C, 04 / 08 / 1989$, Negocios)

(49) En 1996, por ejemplo, el crédito hipotecario sumaba 85.592 millones de euros y el total ascendía a 230.030 millones. (CREA, El País, 02/01/2003, Negocios)

Los usos de pagaba con función modal y evidencial en el contexto económico, político y deportivo están relacionados con informaciones referentes a pagos realizados por empresas (cf. ejemplo 50) o por políticos o instituciones políticas por diversas índoles (cf. ejemplo 51) o pagos realizados a jugadores de equipo de fútbol (cf. ejemplo 52):

(50) VISCOFAN pagaba ayer su dividendo complementario de 15 pesetas brutas por acción, pero la cotización encajó 30 pesetas de pérdida, 
hasta cerrar a 3.130 pesetas. (CREA, La Vanguardia, 06/07/1994, Negocios)

(51) Por esa casa, el Congreso pagaba un alquiler de cerca de medio millón de pesetas al mes. (CREA, El Mundo, 31/03/1996, Política)

(52) En caso de fallecimiento del jugador, el seguro pagaba alrededor de 20 millones de pesetas, aunque fuentes de los clubes indicaron que por lesiones "la cantidad es ridícula". (CREA, El País, 01/10/1985, Deportes)

Con los verbos moría y estallaba, el pretérito imperfecto aparece introducido por fechas exactas o adverbios que puntualizan o delimitan la situación temporalmente. Compárense los siguientes ejemplos (53-56). De ahí que se considere 'anormal' el uso del pretérito imperfecto en estos contextos:

(53) Hace treinta años moría en Pekín, olvidado y pobre, Aisin Gioro Pu Yi, el último Emperador de la última dinastía china. (CREA, $A B C$ Electrónico, 17/10/1997, Actualidad)

(54) En 1976 una bomba estallaba bajo su coche, estacionado frente a su domicilio en Marinha (Cascais), originando importantes destrozos. (CREA, El País, 16/12/1980, Política)

(55) Fernando Bertolá Navarro, de 21 años, había salido de su casa el viernes por la noche para tomar unas copas con un amigo en Majadahonda (Madrid). Horas después, pasadas las dos de la madrugada, moría apuñalado por un joven. [...] (CREA, $A B C$ Electrónico, 29/06/1997, Actualidad)

(56) Prosiguiendo con otros comportamientos antidemocráticos, una bomba estallaba ayer frente a la sede del partido nacionalista croatobosnio HDZ en Sarajevo. (CREA, ABC Electrónico, 14/09/1997, Política)

En los ejemplos anteriores (53-56), el pretérito imperfecto asume el rol principal de la narración y presenta la situación como terminada y concluida. El pretérito imperfecto es usado en vez de una forma verbal perfectiva, tal y como lo explica Bertinetto (1986: 381): El pretérito imperfecto "prendere il posto de un Tempo di natura perfettiva" ("toma el lugar de un tiempo de naturaleza perfectiva'). A este uso del pretérito imperfecto se le conoce también como "imperfecto narrativo" (García Fernández 2004: 14-95, también Fernández Ramírez 1986: 283-284). Según Bertinetto (1986), el uso narrativo del pretérito imperfecto en la prensa es como una variante estilísticamente connotada:

Si es verdad que el imperfecto "narrativo", especialmente en las formas más divulgadas de la prensa, se siente actualmente como una mera 
variante (estilísticamente connotada) de los tiempos perfectivos, no era desde luego así en su origen. (Bertinetto 1986: 381-403)

No obstante, la función narrativa del pretérito imperfecto está asociada a su función modal y evidencial en el sentido de que el hablante cuenta o narra desde su perspectiva una historia, en la cual indica implícitamente que él no es el autor original de la información o no confía en la fuente de información, y por eso no la menciona.

Con respecto al uso del pretérito imperfecto con elementos que marcan explícitamente la actitud epistémica del hablante y la referencia a una fuente externa de información, se obtuvieron los siguientes resultados:

\begin{tabular}{|l|c|c|c|c|c|}
\hline \multirow{2}{*}{ CREA (PERIÓDICOS) } & \multicolumn{2}{|l|}{ VERBOS } & & & \\
\cline { 2 - 6 } & reconocía & ascendia & pagaba & moria & estallaba \\
\hline $\begin{array}{l}\text { TOTAL DE CASOS DE } \\
\text { LA FUNCIÓN MODAL Y } \\
\text { EVIDENCIAL DEL PRETÉRITO } \\
\text { IMPERFECTO EN TODAS LAS } \\
\text { SECCIONES ANALIZADAS }\end{array}$ & $31 \%$ & $11,3 \%$ & $11,5 \%$ & $6 \%$ & $2,5 \%$ \\
\hline $\begin{array}{l}\text { SIN ELEMENTOS QUE MARCAN } \\
\text { LA ACTITUD EPISTÉMICA } \\
\begin{array}{l}\text { DEL HABLANTE Y LA } \\
\text { FUENTE DE INFORMACIÓN }\end{array}\end{array}$ & $27 \%$ & $9 \%$ & $9,2 \%$ & $5 \%$ & $2 \%$ \\
\hline $\begin{array}{l}\text { CON ELEMENTOS QUE MARCAN } \\
\text { LA ACTITUD EPISTÉMICA } \\
\text { DEL HABLANTE Y LA } \\
\text { FUENTE DE INFORMACIÓN }\end{array}$ & $4 \%$ & $2,3 \%$ & $2,3 \%$ & $1 \%$ & $0,5 \%$ \\
\hline
\end{tabular}

Tabla 5. Función modal y evidencial de reconocía, ascendia, pagaba, moría y estallaba sin o con marcadores epistémicos o evidenciales

En la tabla (5) se puede observar que son muy pocos los casos en los que la función modal y evidencial del pretérito imperfecto está explícita mediante el uso de marcadores epistémicos o evidenciales. Obsérvense algunos ejemplos sobre el uso del pretérito imperfecto con elementos que explicitan el conocimiento o la suposición del hablante sobre la situación expresada (cf. ejemplo 57-58) o la referencia a una fuente externa de información (cf. ejemplos 59-60):

(57) Entonces salí de Madrid sabiendo que mi madre se moría porque tenía cáncer. No la volví a ver. Cuando vuelva ahora a Madrid, ya no veré más a Pilar. (CREA, El País, 20/10/1997, Actualidad) 
(58) Además, ETI, en comparación con las opciones de Austria Tabak y Remtsman, supone para Altadis una baza más asequible -el valor estimado de sus acciones en septiembre ascendía a 1.500 millones, y la hispanofrancesa dispone de unos 3.100 millones de capacidad de inversión para afrontar privatizaciones y compras- [...]. (CREA, El País, 16/02/2003, Negocios)

(59) Sus progenitores, dos ancianos con problemas de salud muy pronunciados, ya estaban hartos, "muy hartos", según reconocía la madre. (CREA, El Mundo, 15/03/1996, Actualidad)

(60) Los aliados recibieron alrededor de un $12 \%$ del total que, según fuentes del Foreign Office británico, ascendía a una suma equivalente a 4.000 millones de libras de hoy. (CREA, El País, 19/09/1996, Economía y Hacienda)

La tabla (5) muestra la tendencia del hablante, en este caso, el periodista, de reproducir o transmitir una información mediante el pretérito imperfecto sin hacer referencia o sin hacer mención a la fuente de información, ya sea porque no es necesario mencionar la fuente de información o porque la fuente de información no es confiable. Puede ser que el hablante también considere que reproducir o transmitir el contenido de una información sea más importante que citar la fuente. De todos modos, esta actitud del hablante puede estar relacionada con su distanciamiento frente a sus enunciados, ya sea por reserva, discreción o porque no desea validar completamente el valor de verdad del enunciado.

En el siguiente extracto de un texto periodístico, el hablante (en este caso, el periodista) parece expresarse con mucho cuidado o por lo menos, transmite la información desde su perspectiva sobre la base del conocimiento adquirido de la situación expresada, pero sin mencionar la fuente:

(61) Pakistán, que parecía haberse librado de la lacra del terrorismo, ha visto cómo en solamente seis meses se han multiplicado los atentados indiscriminados, que han dejado un auténtico reguero de muertes. El pasado mes de noviembre, un coche bomba explosionaba junto a la Embajada egipcia. El resultado fue de 17 muertos y 60 heridos; el 1 de diciembre, otra bomba estallaba en un autobús y mataba a tres personas más; ese mismo mes, el día 21, 45 personas fallecían al ser activado un explosivo dentro de un automóvil en Peshawar, mientras que un centenar quedaba herido; apenas transcurridas dos semanas, había que sumar a la lista otras ocho víctimas en Karachi y el pasado 14 de abril sucedía el atentado contra el hospital de Imran Khan -6 muertos y 30 heridos-. A excepción del de la legación diplomática de Egipto, ninguno ha sido reivindicado, aunque se considera 
que Pakistán se ha convertido en terreno abonado para los grupos islamistas extranjeros, que utilizan este país y la guerra afgana como campo de entrenamiento. (CREA, El Mundo, 29/04/1996, Política)

Cuando se trata de informaciones sobre declaraciones dichas o reconocidas por otras personas, ya sea en forma de discurso directo o indirecto, así como sobre pagos, reportes financieros o presupuestos o cualquier informe que esté relacionado con números o cifras parece ser más imporante transmitir el contenido de la información que marcar la fuente de información, como se puede observar mediante los ejemplos con reconocía, ascendía, pagaba (cf. ejemplos anteriores 43-52). Asimismo, cuando se informan sobre sucesos de muertes o accidentes o tragedias parece ser que es más importante decir cuándo sucedió o se llevó a cabo la situación que explicitar de dónde se obtuvo la información. Por eso, todas las informaciones que aparecen con moría y estallaba siempre van introducidas por fechas, días, hora o el año en que se llevó a cabo el suceso (cf ejemplos anteriores 53-56).

\section{CONCLUSIÓN}

El punto de partida para el uso o función modal del pretérito imperfecto es su aspectualidad imperfectiva: una situación expresada en su transcurso sin marcar el inicio o final de la situación, así como la idea de presentar la circunstancias o el fondo de una situación, o sea la indeterminación semántica, hace que la situación presentada en pretérito imperfecto sea considerada como inconclusa y abierta con respecto a su validez (offene Geltung 'validez abierta'). Esta indeterminación lleva a la modalización del pretérito imperfecto, pues el valor de verdad del contenido de la situación queda sin validar, como en Ana salía cuando sonó el teléfono. El hablante no expresa ningún juicio sobre la verdad de la situación expresada en el enunciado, y esto puede estar relacionado con el (no) saber que tiene el hablante sobre la situación (modalidad epistémica) expresada y con el modo de cómo obtuvo o adquirió dicho conocimiento sobre la situación (evidencialidad indirecta). Según se ha podido comprobar en los ejemplos analizados, el pretérito imperfecto puede usarse en determinados contextos con una función modal epistémica para indicar implícitamente el conocimiento o saber (no directo) que tiene el hablante sobre una situación expresada que va asociado con la evidencia de la fuente de información. 
Así, la función evidencial que asume el pretérito imperfecto en todos los ejemplos analizados es indirecta o reportada.

De este modo, el pretérito imperfecto puede comportarse como un marcador evidencial reportativo que indica implícitamente que el hablante no es el autor original de la información. Por medio del pretérito imperfecto, el hablante se distancia de su enunciado y no asume completamente la Regresspflicht ('la obligación de recurso'), es decir, el valor de verdad de su enunciado. En este sentido, cabe mencionar que también el condicional se usa con función evidencial en textos periodísticos escritos, pero a diferencia del pretérito imperfecto que en algunos contextos mantiene sus funciones primarias (aspectual y temporal), el condicional es usado prominentemente en textos periodísticos, como por ejemplo, el condicional francés que es usado como conditionnel journalistique ('condicional periodístico') en textos periodísticos franceses para indicar una 'información reportativa' (cf. Kronning 2002, Sullet- Nylander 2006). En español, el uso del condicional también está relacionado con el discurso directo e indirecto, a lo que Maldonado González (1999: 3553) se refiere como 'oratio quasi oblicua':

Un uso muy frecuente de este recurso se da en los titulares periodísticos, en los que la presencia de un condicional sirve para que el emisor (el periodista, en este caso) se apropie de una opinión, una noticia o un mensaje ajeno y los reformule como propios, sin comprometerse del todo con la verdad de la enunciación: a) Se convocaría la huelga, b) Se firmaría el acuerdo (Maldonado González 1999: 3553).

Al parecer, la prensa se vale de diversos medios lingüísticos para referirse a citas y a enunciados dichos por otros, sobre todo, cuando no se menciona la fuente de información porque es desconocida o no es confiable. En este sentido, el pretérito imperfecto parece estar capacitado para asumir la función de un marcador evidencial en forma implícita, aunque -como ya se ha mencionado anteriormente- todavía pueda ser usado con valores aspectuales y temporales, lo que no ocurre con el condicional cuyo uso aparentemente se ha especializado en textos periodísticos escritos en el francés y el español.

Desde el punto de vista pragmático la función evidencial del pretérito imperfecto corresponde a sus usos secundarios relacionados con la actitud epistémica del hablante frente a su enunciado y la fuente de información, pero no con sus usos secundarios relacionados con la actitud del hablante frente a su interlocutor que corresponden a los usos modalizados del pretérito imperfecto en el contexto oral discursivo, como 'imperfecto de cortesía', 'imperfecto de deseo', 'imperfecto onírico', etc. Por eso, el uso secundario evidencial del pretérito imperfecto se subsume bajo la noción de evidencialidad indirecta (Böhm 2016: 21) y en vista de que las lenguas 
romances, como el español, no marcan la evidencialidad mediante sufijos o partículas gramaticales como lo hacen las lenguas con sistema evidencial propio, por ejemplo, el Tuyuca y el Quechua, las formas temporales en español y también en francés, como el pretérito imperfecto, futuro y condicional parecen ser un recurso para marcar la evidencialidad (cf. Haßler y Böhm 2019: 210).

También se ha comprobado que los verbos puntuales y perfectivos -llamados o conocidos como 'modos de acción'- motivan el uso modal y evidencial del pretérito imperfecto, ya que por su naturaleza léxica de llevar intrínsicamente una marca o un límite temporal interno deberían ser usados en la forma perfectiva (pretérito perfecto simple). Entonces, al ser usados en la forma imperfectiva se distorsiona su significado original. Véase la siguiente tabla:

\begin{tabular}{|l|l|}
\hline $\begin{array}{l}\text { VERBOS / } \\
\text { 'MODOS DE ACCIÓN' }\end{array}$ & $\begin{array}{l}\text { FORMA PERFECTIVA (PRETÉRITO PERFECTO SIMPLE) } \\
\text { VS. FORMA IMPERFECTIVA (PRETÉRITO IMPERFECTO }\end{array}$ \\
\hline reconocer & reconoció vs. reconocía \\
\hline ascender & ascendió vs. ascendia \\
\hline pagar & pagó vs. pagaba \\
\hline morir & murió vs. moría \\
\hline estallar & estalló vs. estallaba \\
\hline
\end{tabular}

Tabla 6. Modos de acción en la forma perfectiva vs. forma imperfectiva

Del mismo modo, algunos elementos léxico-semánticos, como por ejemplo, los adverbios temporales, como ayer, horas después, etc. o elementos temporales que introducen la fecha, la hora o el año en los cuales un suceso o una situación tuvo lugar, así como elementos sintácticos, como declaraciones hechas por personas en forma de discurso directo e indirecto seguido o antecedido por el pretérito imperfecto (por ejemplo, [proposición (discurso directo)] + reconocía o reconocía + [proposición (discurso directo / indirecto)] y estructuras sintácticas formadas por la preposición $a+$ números / cifras (por ejemplo, ascendía a + números/cifras) corroboran o contribuyen con la función modal y evidencial del pretérito imperfecto. En todos los casos en los que el pretérito imperfecto asume una función modal y evidencial aparece el pretérito imperfecto como el elemento principal sintáctico en la oración o enunciado.

De todos los casos analizados, reconocía y ascendía parecen ser usos sistemáticos del pretérito imperfecto, ya que en todos los casos de reconocía (31\%) la función modal y evidencial está relacionada con declaraciones hechas por personas sobre situaciones o sobre una realidad y en todos los 
casos (11,3\%) ascendía aparece en combinación de la preposición $a+$ números. En los casos de pagaba solo el contexto determina su función modal y evidencial, por ejemplo, el seguro pagaba alrededor de 20 millones de pesetas (cf. ejemplo 52). En la mayoría de los casos de moría y estallaba la función modal y evidencial del pretérito imperfecto se refuerza por la presencia de elementos adverbiales que delimitan temporalmente la situación, por ejemplo, horas después, pasadas las dos de la madrugada, moría apuñalado por un joven. [...] (cf. ejemplo 55) o el pasado mes de noviembre, un coche bomba explosionaba junto a la Embajada egipcia (cf. ejemplo 61).

Finalmente, se puede establecer una relación entre la aspectualidad imperfectiva del pretérito imperfecto, modalidad epistémica y evidencialidad indirecta sobre la base de la indeterminación semántica, es decir, de presentar una situación con validez abierta (offene Geltung): Mientras que la aspectualidad imperfectiva presenta una situación en su desarrollo y transcurso sin proporcionar detalles sobre el inicio o final de la misma, por lo que la situación se considera abierta e indeterminada en cuanto a su término (por ejemplo, el tren llegaba a las ocho), en la modalidad epistémica no se expresa ningún juicio sobre el valor de la verdad de una situación (por ejemplo, creo que el tren llega a las ocho), por lo que el valor de verdad está también indeterminado o abierto, y en la evidencialidad indirecta el hablante indica que él no es el autor original de la información, y hace referencia a una fuente externa de la información, distanciándose así de su enunciado, por lo que la situación expresada por el hablante también queda sin validar (por ejemplo, según me informaron, el tren llega(ba) a las ocho). Entonces, tanto en la aspectualidad imperfectiva como en la modalidad epistémica y en la evidencialidad indirecta, el valor de verdad de la situación está abierto en cuanto a su validez, y el pretérito imperfecto por su carácter imperfectivo e indeterminado, tal y como se ha analizado y comprobado en los ejemplos del corpus, parece cumplir con todos los requisitos para comportarse como un marcador modal epistémico y evidencial indirecto en determinados contextos.

REFERENCIAS BIBLIOGRÁFICAS

Bazzanella, Carla. 1990. "Modal” uses of the Italian Indicativo Imperfetto in a pragmatic perspective. Journal of Pragmatics 14: 439-457.

BARNES, JANET. 1984. Evidentials in the Tuyuca verb. International Journal of American Linguistics 50/3: 255-271. 
Bello, ANDrés. 1988. Gramática de la lengua castellana: Destinada al uso de los americanos. Madrid: Arco Libros.

Bertinetto, Pier Marco. 1986. Tiempo, aspetto e azione nel verbo italiano: Il sistema dell'indicativo. Florenz: Presso L'Academia della Crusca.

BöHM, Verónica. 2016. La imperfectividad en la prensa española y su relación con las categorías semánticas de modalidad y evidencialidad. Peter Lang: Frankfurt am Main.

BReS, JACQUes. 2005. L'imparfait dit narratif. CNRS Èditions: Paris.

Bybee, Joan y Suzanne Fleischmann. 1995. Modality in Grammar and Discourse. An Introductory Essay. En Joan Bybee y Suzanne Fleischmann (coords.). Modality in Grammar and Discourse, pp. 1-14. Amsterdam/ Philadelphia: John Benjamins Publishing Company.

COMrie, Bernard. 1976. Aspect, an introduction to the study of verbal aspect and related problems. Cambridge: Cambridge University Press.

CORPUS DEL ESPAÑOL (CdE). http://www.corpusdelespanol.org/.

Corpus de la Real ACADEMia ESPAÑola (CREA). http://corpus.rae.es/creanet.html.

Dessì SCHMID, SARAH. 2010. 'Modal uses' of the Italian imperfetto and the Spanish imperfecto: a comparison. En Martin G. Becker y Eva-Maria Remberger (coords.). Modality and Mood in Romance: Modal Interpretation, Mood Selection, and Mood Alternation, pp. 39-66. Tübingen: Niemeyer/De Gruyter.

Díaz Salgado, Luis C. 2000. La Decoración del Drama. Venezuela Analítica. Núm. Nov. 2000: 1-1 [en línea]. Disponible en http://www.buenastareas.com/ensayos/LaDecoraci\%C3\%B3n-Del-Drama/3864447.html [Consulta 29/09/2020].

Dietrich, RaINer. 1992. Modalität im Deutschen. Zur Theorie der relativen Modalität. Opladen: Westdeutscher Verlag.

FERnÁNDEZ RAmírez, SALVADOR. 1986. Gramática Española. 4. El verbo y la oración. Volumen ordenado y competado por I. Bosque, Madrid: Arco/Libros.

García Fernández, LuIs. 2004. El pretérito imperfecto: Repaso histórico y bibliográfico. En Luis García Fernández y Bruno Camus Bergareche (coords.). El pretérito imperfecto, pp. 13-95. Madrid: Gredos.

Givón, Talmy. 1982. Evidentiality and Epistemic Space. Studies in Language 6.3: 23-49.

Gutiérrez Aráus, María Luz. 1995a. Formas temporales del pasado en indicativo. Madrid: Arco Libros.

1995b. Sobre los valores secundarios del imperfecto. ASELE, Actas VI (León 5-7 de octubre 1995): 177-186.

Hassler, Gerda. 1997. Texte im Text. Überlegungen zu einem textlinguistischen Problem. En Gerda Haßler (coord.). Texte im Text: Untersuchungen zur Intertextualität und ihren sprachlichen Formen, pp. 11-58. Münster: Nodus.

2008. Recursos evidenciales en las lenguas romances: un estudio funcional y comparativo. En Franciso M. Carriscondo Esquivel y Carsten Sinner (coords.). Lingüística española contemporánea. Enfoques y soluciones, pp. 225-243. München: Anja Gärtig Verlag.

2012. Indicative Verb Forms as Means of Expressing Modality in Romance Languages. En Werner Abraham y Elisabeth Leiss (coords.). Covert Patterns of Modality, pp. 133-152. Cambridge: Cambridge Scholars.

2016. Temporalität, Aspektualität, Modalität in romanischen Sprachen. Berlin/ Boston: De Gruyter.

HASSLER, GERDA Y VerónICA BöHM. 2019. La integración de la aspectualidad como categoría semántico-funcional en la lingüística española. En Dolores García Padrón, Héctor Hernández Arocha y Carsten Sinner (coords.). Clases y categorías en la semántica del 
español y sus interfaces, pp. 195-216. Beihefte zur Zeitschrift für romanische Philologie. Berlin, Boston: De Gruyter,. https://doi.org/10.1515/9783110637700-009.

KronNing, Hans. 2002. Le conditionnel 'journalistique': médiation et modalisation épistémiques. Romansk Forum 16(2): 561-575.

LeONTARIDI, Eleni. 2001. Los tiempos del pasado del indicativo en español y en griego moderno. Tesis doctoral. Universidad de Salamanca, Facultad de Filología.

Lyons, John. 1977. Semantics. Cambridge: University Press.

Maldonado GonzÁlez, ConcePción. 1999. Discurso directo y discurso indirecto. En Bosque, Ignacio y Violeta Demonte (coords.). Gramática descriptiva de la lengua española, pp. 3549-3595. Madrid: Espasa Calpe.

NUYTS, JAN. 2005. The modal confusion: on terminology and the concepts behind it. En Alex Klinge y Henrik Høeg Müller (coords.). Modality, Studies in Form and Function, pp. 5-38. Oakville: Equinox Publishing Ltd.

Palmer, Frank. 1986. Mood and Modality. Cambridge: Cambridge University Press.

Real ACAdemia EsPañola. 2009. NGLE: Nueva gramática de la lengua española. Madrid, Espasa Libros.

Reyes, Graciela. 1990. Tiempo, modo, aspecto e intertextualidad. Revista Española Lingüística 1, 20: 17-53.

1994. Los procedimientos de cita: citas encubiertas y ecos. Madrid: Arco Libros.

Rojo, Guillermo y Alexandre Veiga. 1999. El tiempo verbal. Los tiempos simples. En Ignacio Bosque y Violeta Demonte (coords.). Gramática descriptiva de la lengua española [Vol. 2], pp. 2867-3208. Madrid: Espasa Calpe.

Sullet- Nylander, Françoise. 2006. Paratexte, contexte et intertexte dans Le Monde (2005): conditionnels journalistiques et discours rapportés. Pratiques 129/130: 123-138.

Volkmann, Gesina. 2005. Weltsicht und Sprache. Epistemische Relativierung am Beispiel des Spanischen. Tübingen: Gunter Narr Verlag.

Wachtmeister Bermúdez, Fernando. 2005. Evidencialidad. La codificación lingüistica del punto de vista. Tesis doctoral. Stockholms Universitet.

Willett, ThOMAs. 1988. A cross-linguistic survey of the grammaticization of evidentiality. Studies in Language Vol. 12, Nr. 1: 51-97. 